\title{
PHOTOCHEMICALLY CATALYSED POLYMERISATION OF 3-TRIMETHOXYSILYLPROPYL METHACRYLATE CONTAINING SILVER, COPPER AND ZINC IONS
}

\author{
"VERONIKA MÁKOVÁ**,***, MICHAL ŠPÍNA*, JANA MÜLLEROVÁ**,***, PETR EXNAR**,*** \\ *Department of New Technologies and Applied Informatics, Faculty of Mechatronics and Interdisciplinary Studies, \\ Technical University of Liberec, Studentská 1402/2, 46117 Liberec 1, Czech Republic \\ **Department of Nanomaterials in Natural Sciences, Institute for Nanomaterials, Advanced Technologies and Innovation, \\ Technical University of Liberec, Studentská 1402/2, 46117 Liberec 1, Czech Republic \\ ***Department of Chemistry, Faculty of Science, Humanities and Education, Technical University of Liberec, \\ Studentská 1402/2, 46117 Liberec 1, Czech Republic \\ "E-mail: veronika.makova@tul.cz
}

Submitted April 12, 2018; accepted July 16, 2018

\begin{abstract}
Keywords: 3-Trimethoxysilylpropylmethacrylate, Photoinitiator, Polymerisation, Hybrid Matrix, Infrared spectroscopy
Photo curable organic-inorganic monomers are currently generating much interest in many research groups worldwide due to their unique properties leading to a wide range of applications including electronics, energetics, medicine, etc. One of them, 3-trimethoxysilylpropylmethacrylate belongs to the class of such monomers having a wide range of relatively good mechanical, chemical and physical properties. Moreover, this monomer can be cured by different processes including heat treatment and light. Photochemically catalysed polymerisation of sol prepared from 3-trimethoxysilylpropylmethacrylate hybrid monomer and titanium tetraisopropoxide containing silver, copper and zinc ions was tested with two commercially available photoinitiators, a Darocur 1173 and an Irgacure 819. The aim of this study was to propose conditions for the effective polymerisation process leading to the maximal conversion of double bonds present in the organic part of the hybrid monomer and observe the potential effect of the ions. Particularly the copper ions by themselves and/or in combination with silver ions inside the hybrid matrix may influence the speed and conversion degree of the photochemically catalysed polymerisation processes.
\end{abstract}

\section{INTRODUCTION}

Organoalkoxysilanes constitute an excellent challenge in current high-tech applications, particularly thanks to the combination of inorganic and organic parts, which are able to further tune the material properties. The inorganic part is anticipated to improve the mechanical and thermal stability, whereas the organic part can enhance the flexibility and toughness of the formed hybrid material. The unique structural properties, compositional and shape flexibility from these materials provide promising and high application potential in different fields of industry, and/or daily life [1]. The first hybrid materials have been commercially available since 1950 [2], and their current uses are presented in energetics [3], optics [4], microelectronics [5], and/or biosensors [6].

In general, hybrid materials can be processed in different forms as gels [7, 8], monoliths [9], thin films [10], fibres [11] or particles [12]. Likewise, different techniques may be used to form hybrid materials from organoalkoxysilanes; sol-gel condensation [13], radical polymerisation induced by light [14] or temperature [15], cationic/anionic polymerisation [16, 17], sol-gel induced by light [18]. The photo induced sol-gel chemistry offers a one-step synthesis of many UV cured organoalkoxysilanes. The advantage consists in the addition of a hydrolysable sol-gel precursor to the conventional radically UV curable component without the necessity to optimise the catalytic conditions for the sol-gel process [18].

Until now, these hybrid sol-gel photomaterials have been synthesised in solutions from radically reactive organoalkoxysilanes through a preliminary sol-gel reaction, which was followed by the photochemically catalysed polymerisation of the resulting functional polysilsesquioxane [18]. On the contrary to this, Soucek et al. [19] firstly used tetraethylorthosilicate (TEOS) and reactive organoalkoxysilanes, which were formed in a preliminary sol-gel step, and subsequently mixed them with radically reactive resins for further polymerisation $[20,21]$. These organoalkoxysilanes were used as grafting or coupling agents with the aim to enhance the nanoparticles or metal alkoxides dispersion in a radically photo-curable organic host matrix $[18,22]$. 
Nowadays, UV curable hybrids are used in the form of coatings, inks, adhesives, micro-electronics, 3D printing or in laser recording materials [23]. One of the widely used UV curable organoalkoxysilanes forming hybrid materials is 3-(trimethoxysilyl)propyl methacrylate (TMSPM), either in a pure form or in combination with silica alkoxides, e.g., tetraethylorthosilicate, which supports both organic and inorganic polymerisation processes and is known as a good sol-gel precursor. TMSPM is of a great interest to obtain hybrid materials for a large variety of photonic [24] and biomedical applications [25] thanks to the presence of hydrolysable functional groups and carbon-carbon double bond in its molecule. By varying the reaction conditions such as hydrolysis, solvent, initiator type, the final product can be tailored for specific purposes in terms of the optical, mechanical and chemical properties [26]. TMSPM belongs to the hybrids allowing for the encapsulation of different metallic nanoparticles such as $\mathrm{Ag}, \mathrm{Cu}, \mathrm{Zn}$ and $\mathrm{Au}$ [27]. Among the other metallic nanoparticles, the trio of silver, copper and zinc attracted the most attention due to their unique biocidal activities [28].

TMSPM belongs to the monomers where the polymerisation processes induced by light can be effectively applied, thanks to the presence of active carbon-carbon double bond. From this point of view, we have chosen two photoinitiators suitable for attacking the double bond. 2-Hydroxy-2-methyl-1-phenyl-propan-1-one, commercially known as DAROCUR 1173, the liquid photoinitiator usually used to initiate mono or multifunctional monomers having the main activity in the UV A region at $365 \mathrm{~nm}$ [33] and Bis(2,4,6-trimethylbenzoyl)-phenylphosphineoxide, commercially known as Irgacure 819, which can be easily used in combination with UV absorbers due to its photosensitivity at longer wavelengths between 380 - $400 \mathrm{~nm}$ [34].

In our previous studies [30,35], we have reported the preparation of a new type hybrid coating based on 3-(trimethoxysilyl)propyl methacrylate (TMSPM) containing silver and copper ions with a strong antibacterial effect against a variety of pathogenic bacteria including Staphylococcus aureus and its methicillin-resistant variant [30]. Subsequently, we have published the results related to its antivirotic activity on different types of viruses including HIV, Dengue, Herpes simplex, Coxsackie and Influenza viruses [35]. In relation to our previous articles, this article is focused on the optimisation of the conditions for an effective polymerisation induced by light and the suitability of the photoinitiators (Darocur 1173, Irgacure 819) tested with a combination of the $\mathrm{Ag}, \mathrm{Cu}$ and $\mathrm{Zn}$ ions presented in the prepared hybrid matrix while maintaining its antibacterial and antivirotic properties. The influence of various parameters on the curing degree of TMSPM (photo initiator type, its amount, curing time and light conditions) were investigated. The process of photochemically catalysed polymerisation was determined by Fourier transform infrared (FTIR) spectroscopy.

\section{EXPERIMENTAL}

\section{Materials}

3-(trimethoxysilyl)propyl methacrylate (TMSPM, $98 \%$, Sigma-Aldrich), titanium isopropoxide (IPTI, $>97 \%$, Sigma-Aldrich), silver nitrate $\left(\mathrm{AgNO}_{3}, 99.8 \%\right.$ Sigma-Aldrich), copper nitrate trihydrate $\left(\mathrm{Cu}\left(\mathrm{NO}_{3}\right)_{2}\right.$. $\cdot 3 \mathrm{H}_{2} \mathrm{O}, 98-103 \%$, Sigma-Aldrich), zinc nitrate hexahydrate $\left(\mathrm{Zn}\left(\mathrm{NO}_{3}\right)_{2} \cdot 6 \mathrm{H}_{2} \mathrm{O}, 98 \%\right.$, Sigma-Aldrich), propan-2-ol (99.98\%, Penta CZ), nitric acid $\left(\mathrm{HNO}_{3}, 65 \%\right.$, Lach:ner CZ), distilled water, photoinitiator Irgacure 819 (45 \%, Ciba CZ), photoinitiator Darocur 1173 ( $97 \%$, Sigma-Aldrich) were used.

\section{Methods}

\section{General synthesis of Sol 6}

Silver nitrate (32 mg, $0.19 \mathrm{mmol}$ ) was dissolved in $10 \mathrm{ml}(130 \mathrm{mmol})$ of propan-2-ol by stirring at room temperature (RT) for $60 \mathrm{~min}$. Subsequently, TMSPM $(1.0 \mathrm{ml}, 4.21 \mathrm{mmol})$ was added via a septum into the flask and the mixture was stirred at $350 \mathrm{rpm}$ for $30 \mathrm{~min}$ in an inert atmosphere. After that, $(0.08 \mathrm{ml}, 4.17 \mathrm{mmol})$ of a $2 \mathrm{M}$ solution of nitric acid and distilled water $(0.08 \mathrm{ml}, 4.44 \mathrm{mmol})$ were added into the solution. In the intervening time, copper nitrate trihydrate $(77 \mathrm{mg}$, $0.96 \mathrm{mmol}$ ) and zinc nitrate hexahydrate $(92 \mathrm{mg}$, $1.86 \mathrm{mmol})$ were dissolved in $10 \mathrm{ml}(130 \mathrm{mmol})$ of propan-2-ol in a separate flask and added to the main solution with an increased stirring rate of $750 \mathrm{rpm}$. Finally, IPTI $(0.65 \mathrm{ml}, 2.22 \mathrm{mmol})$ was dropped into the

Table 1. Composition of all the tested sols.

\begin{tabular}{lcccccccc}
\hline & TMSPM & IPA & IPTI & $\mathrm{HNO}_{3}$ & $\mathrm{H}_{2} \mathrm{O}$ & $\mathrm{AgNO}_{3}$ & $\mathrm{Cu}_{\left(\mathrm{NO}_{3}\right)_{2} \cdot 3 \mathrm{H}_{2} \mathrm{O}}$ & $\mathrm{Zn}\left(\mathrm{NO}_{3}\right)_{2} \cdot 6 \mathrm{H}_{2} \mathrm{O}$ \\
\hline & & & \multicolumn{7}{c}{$\left(\mathrm{ml} \cdot \mathrm{mmol}^{-1}\right)$} \\
Sol 1 & $1 / 4.21$ & $20 / 261$ & $0.65 / 2.22$ & $0.10 / 5.22$ & $0.11 / 6.11$ & $0 / 0$ & $0 / 0$ & $0 / 0$ \\
Sol 2 & $1 / 4.21$ & $20 / 261$ & $0.65 / 2.22$ & $0.10 / 5.22$ & $0.11 / 6.11$ & $30 / 0.18$ & $0 / 0$ & $0 / 0$ \\
Sol 3 & $1 / 4.21$ & $20 / 261$ & $0.65 / 2.22$ & $0.10 / 5.22$ & $0.10 / 5.55$ & $0 / 0$ & $73 / 0.91$ & $0 / 0$ \\
Sol 4 & $1 / 4.21$ & $20 / 261$ & $0.65 / 2.22$ & $0.09 / 4.70$ & $0.09 / 5.00$ & $0 / 0$ & 0 & $87 / 1.75$ \\
Sol 5 & $1 / 4.21$ & $20 / 261$ & $0.65 / 2.22$ & $0.10 / 5.22$ & $0.10 / 5.55$ & $31 / 0.18$ & $75 / 0.31$ & $0 / 0$ \\
Sol 6 & $1 / 4.21$ & $20 / 261$ & $0.65 / 2.22$ & $0.08 / 4.17$ & $0.08 / 4.44$ & $32 / 0.19$ & $77 / 0.96$ & $92 / 1.86$ \\
\hline
\end{tabular}


reaction mixture, which was stirred for another $15 \mathrm{~min}$. The resulting sol was refluxed in an oil bath at $92^{\circ} \mathrm{C}$ while being stirred for $35 \mathrm{~min}$, then cooled down to RT and stored in a polyethylene flask in the dark at $20^{\circ} \mathrm{C}$. All the sols thus prepared (see Table 1) were used within three weeks.

\section{Light conditions of the curing process}

The spectrum of the light source was measured by a Flame (Ocean Optics) spectrometer. The peak value of the irradiation was $365 \mathrm{~nm}$. The irradiation intensity for the photoinitiated polymerisation was measured with and optimised using a PM100D - Compact Power and Energy Meter Console (Thorlabs). The intensity of the incident light was set at the value of $0.5 \mathrm{~mW} \cdot \mathrm{m}^{-2}$ after transmission through the wall of the vial used.

\section{Polymerisation procedure}

TMSPM was used as the monomer. All the prepared sols were mixed with the chosen photoinitiators. The first tested photoinitiator was Darocur 1173; supplied in liquid form. A stock solution for each series of samples with one type of sol (1-6) was prepared from $6.8 \mathrm{ml}$ of the tested sol and $10 \mu \mathrm{l}$ of Darocur 1173. Both components were mixed together for $30 \mathrm{s.} 1 \mathrm{ml}$ of each sol was dosed into a vial and subsequently irradiated with UV A light (peak value at $365 \mathrm{~nm}$, light intensity $0.5 \mathrm{~mW} \cdot \mathrm{m}^{-2}$ ).

The second photoinitiator Irgacure 819 was tested according to the following ratio (Irgacure 819; $59 \mu \mathrm{l}$ of 1 wt. $\%$ solution in acetonitrile and $1 \mathrm{ml}$ of each sol). The samples were irradiated by the same procedure used for Darocur 1173. All the samples were cured in a UV A light. Sols 1-3 were cured in the following time intervals $30 ; 45 ; 60 ; 90$ and 120 minutes. The time interval for sol 4 was increased up to 150 minutes and sols 5-6 were irradiated up to 180 minutes. The time prolongation in the above-mentioned experiments was necessary due to the significant decrease in speed in the polymerisation process, most probably caused by the presence of the copper ions in sols 4-6.

\section{FTIR spectroscopy}

A FTIR Spectrometer Nicolet iZ10 (ThermoScientific, USA) with an ATR Ge crystal angle $45^{\circ}$, a spectral range: $4000-700 \mathrm{~cm}^{-1}$ was used for the analysis of all the prepared samples. The number of sample scans: 16 , the number of the background scans: 32 , resolution: $4 \mathrm{~cm}^{-1}$, gain: 4.0, Apodization: Happ-Genzel, Correction: Atmospheric suppression, Baseline. Using ATR techniques, there is no constant absorption pathway for the individual samples, so the so-called spectrum is needed to normalise it to the same bandwidth intensity that should not change during the reaction. From this point of view, we decided to normalise to the bandwidth of $1040 \mathrm{~cm}^{-1}$. This bandwidth corresponds to the valence vibration of the $\mathrm{Si}-\mathrm{O}-\mathrm{Si}$ bonds, where we assume the smallest changes during UV curing process.
Each sol, before irradiation process, was chosen as the reference (zero value). The polymerisation kinetics data was obtained using transmission FTIR spectroscopy by monitoring the decrease of the carbon-carbon double bonds at $1630 \mathrm{~cm}^{-1}$. The absorbance value was subtracted from the baseline between $1655 \mathrm{~cm}^{-1}$ and $1590 \mathrm{~cm}^{-1}$. The series with a defined irradiation time was stated for a group of samples with the same composition for each sol (1-6). The samples were pulled away from the UV A source in the above-mentioned time intervals and the obtained absorbance of the double bond peak were plotted to chart them in dependence on time.

\section{RESULTS AND DISCUSSION}

\section{FTIR spectroscopy}

FTIR analyses were used to observe the double bond decrease and behaviour during the UV curing process when using two different types of photoinitiators (Darocur 1173 and Irgacure 819). The obtained data was subsequently used to determine the kinetics and conversion degree of each tested sol.

\section{Effect of the tested photoinitiators}

The suitability of a given photoinitiator and its effect on the rate of polymerisation are dependent on its solubility or dispersibility in the monomers and alternatively the polymers and their activation wavelength. The liquid photoinitiator, Darocur 1173, was observed to form a homogeneous mixture with all the tested sols, whereas the solid photoinitiator, Irgacure 819 , was originally solid and had to be firstly diluted in acetonitrile. Figures 1 and 2 show polymerisation kinetics in time for sol 6 containing different types of ions and their combination using two different photoinitiators under the same curing conditions (UV A light, intensity $0.5 \mathrm{~mW} \cdot \mathrm{m}^{-2}$, peak maximum $365 \mathrm{~nm}$ ). The highest rate of polymerisation and final double-bond conversion were obtained in the case of sol 1 containing Darocur 1173, where the double-bond conversion reached almost $95 \%$ in $120 \mathrm{~min}$ (Figure 3). Contrary to this, the final conversion of sol 1 using Irgacure 819 reached only $50 \%$ in the same time interval (Figure 4). Therefore, Darocur 1173 was deemed to be the most efficient photoinitiator because of the good solubility in all sols at RT, which is facilitated by the liquid-liquid diffusion and might be responsible for its relatively good curing efficiency, moreover, due to the light wavelength at $365 \mathrm{~nm}$.

In general, methacrylates have a tendency to form less stable tertiary radicals and the rate retarding steric effect of the methyl group may prevail. Moreover, methacrylate monomers are reported to be more oxygen inhibited than acrylate monomers [36].

The polymerisation process is characterised by the dependence of the absorbance (intensity) of the $\mathrm{C}=\mathrm{C}$ band with a maximum of $1630 \mathrm{~cm}^{-1}$ on the reaction 
time (min). Conversion dependence on the reaction time is not linear (Figures 3 and 4). Conversion values were determined estimating two points: conversion $0 \%$ and $100 \%$ at time 0 (assumption $0 \%$ ) and at a time when the absorbance value does not change any further (assumption $100 \%$ ). $100 \%$ conversion can also be assumed at zero absorbance of the double bond band. However, experiments have shown that a $100 \%$ conversion can not be achieved by the polymerisation technique.

\section{Photoinitiator concentration and its possible effect}

The used concentrations of the photoinitiators were set on the basis of previous studies. Tripathy et al. [37] reported a study related to aliphatic PIB triol (meth) acrylates, where effective polymerisation occurred, when the concentration of the initiator (Darocur 1173) was between 2 and 3 wt. \%. In addition, the rapid photolysis of an initiator creates a high concentration of

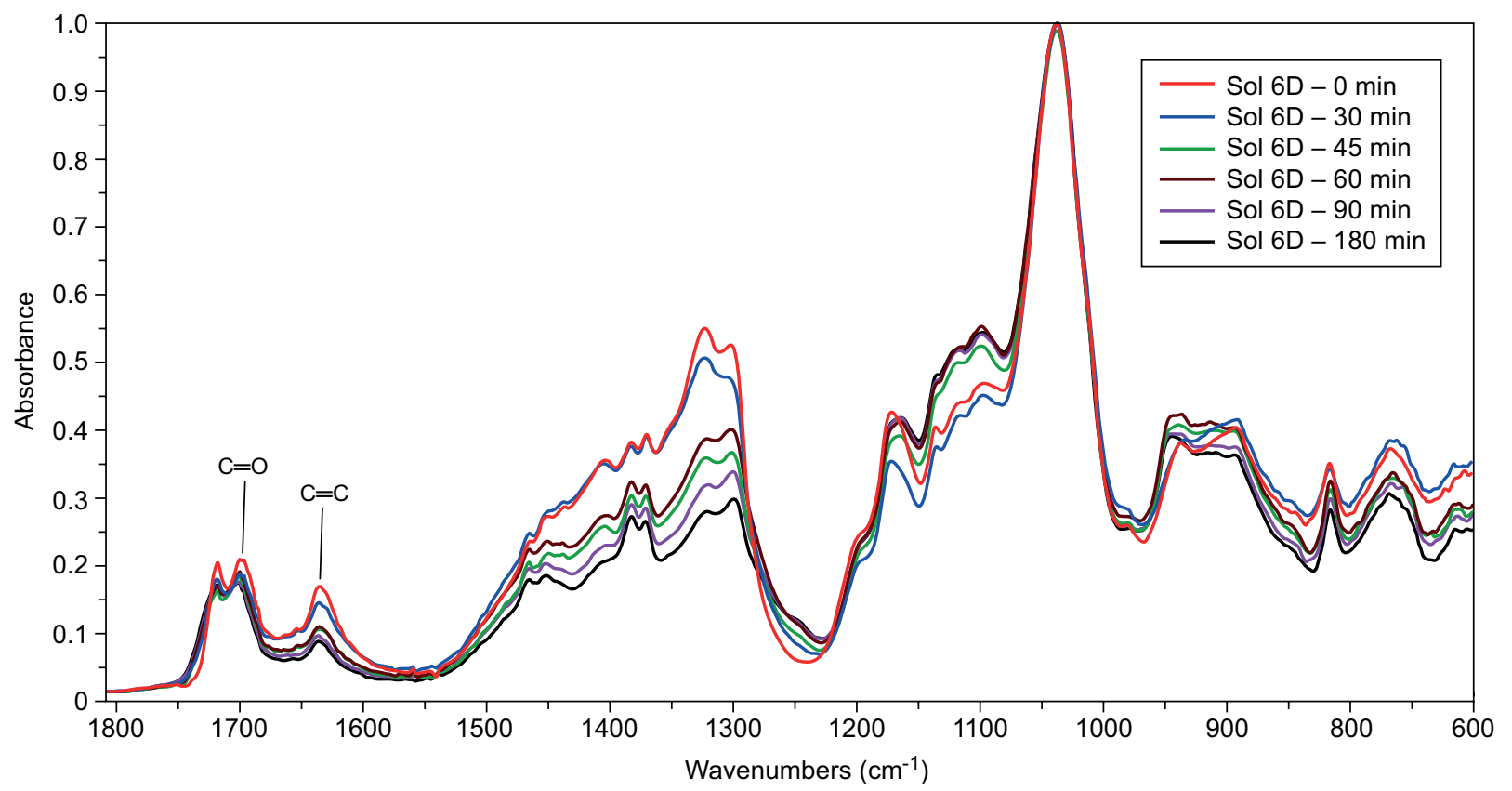

Figure 1. UV curing of sol 6 in time with Darocur 1173.

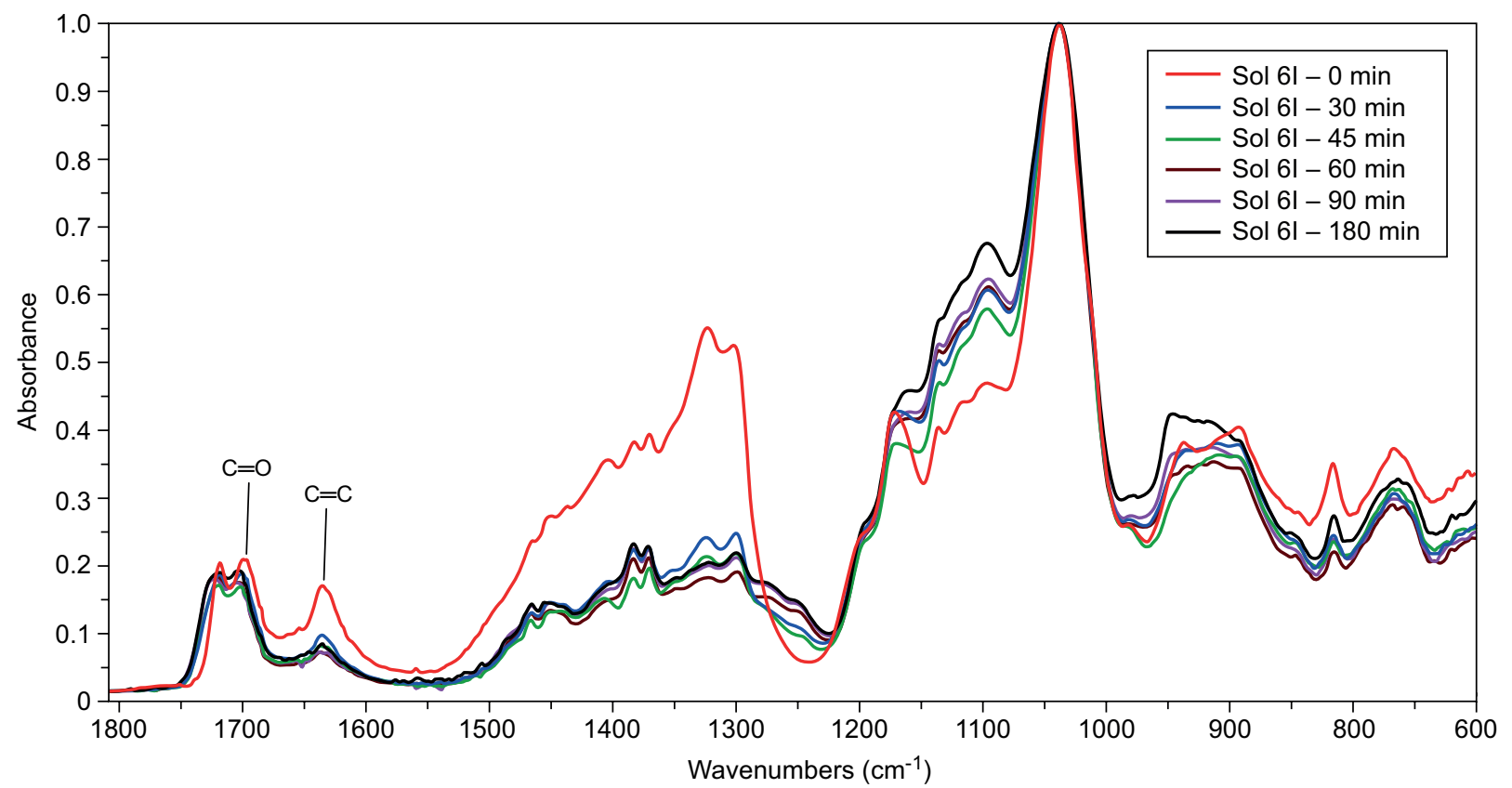

Figure 2. UV curing of sol 6 in time with Irgacure 819. 
active free radicals, which is essential for a high rate of polymerisation (from 1 to $2 \mathrm{wt}$. \%), but it may lead to the premature termination of the polymerisation due to competitive radical- radical coupling reactions (from 2 to 3 wt. \%).

We can assume that a moderate concentration of both photoinitiators helps increase the rate of polymerisation and the curing efficiency, but a higher concentration of the photoinitiator does not guarantee a faster curing profile and may introduce defects into the networks due to the high initiator residues. In our case, the kinetics of the polymerisation process for the TMSPM systems was studied with respect to the photoinitiator concentration (2.5 wt. \% of Darocur 1173 and 1 wt. \% for Irgacure 819). The determined concentration of both tested photoinitiators was sufficient for the polymerisation process leading to the maximal possible conversion of the double bonds in the TMSPM system, the presence of the ions for both tested photoinitiators significantly influenced (decreased) the speed of the curing processes and conversion degrees of TMSPM.

\section{Effect of UV light intensity}

One of the unique advantages of polymerisation is the precise temporal control of the initiation step, by specifying both the onset and duration of light, as well as the rate control, by specifying light intensity. If desired, the initiation rate can even be varied over the course of polymerisation through adjustments in light intensity. The kinetics of the TMSPM polymerisation with two different photoinitiators Darocur 1173 and Irgacure 819 was studied with respect to UV light intensity $\left(0.5 \mathrm{~mW} \cdot \mathrm{m}^{-2}\right)$. For TMSPM, the chosen intensity led to a higher curing conversion in the case of Darocur 1173 compared to Irgacure 819 . The final conversion of TMSPM (sol 1) went up from $0 \%$ to almost $95 \%$ in $120 \mathrm{~min}$ at a UV light intensity of $0.5 \mathrm{~mW} \mathrm{~m}^{-2}$ in the case of Darocur 1173. Contrary to this, Irgacure 819 provided a maximum conversion for sol 1 up to $50 \%$ in $120 \mathrm{~min}$ with using the same light conditions, see Table 2.

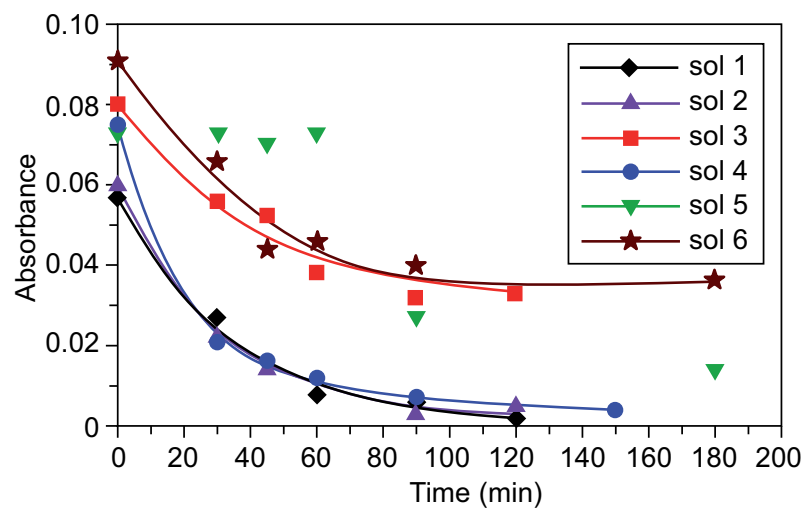

Figure 3. Kinetics of sols 1-6 polymerised by Darocur 1173 containing different ions and their combination.
Table 2. Conversion degrees of TMSPM achieved by the tested photoinitiators.

\begin{tabular}{lcccc}
\hline & $\begin{array}{c}\text { Darocur 1173 } \\
\text { conversion (\%) }\end{array}$ & $\begin{array}{c}\text { Time } \\
(\mathrm{min})\end{array}$ & $\begin{array}{c}\text { Irgacure 819 } \\
\text { conversion (\%) }\end{array}$ & $\begin{array}{c}\text { Time } \\
(\mathrm{min})\end{array}$ \\
\hline Sol 1 & 95 & 120 & 50 & 120 \\
Sol 2 & 90 & 120 & 70 & 120 \\
Sol 3 & 55 & 120 & 50 & 90 \\
Sol 4 & 85 & 150 & 100 & 180 \\
Sol 5 & 70 & 180 & 75 & 180 \\
Sol 6 & 50 & 180 & 50 & 180 \\
\hline
\end{tabular}

Decker [36] explained in his work that the high rate of polymerisation and high curing efficiency originating from high UV light intensity is attributed to two main factors: (i) a higher sample temperature resulting in high polymer chain mobility and a high final conversion; (ii) a longer time lag between the conversion and shrinkage, which forms an excess free volume and thus increases the polymer chain mobility, as well an increase in the UV light moderate concentration of the photoinitiator which helps increase the rate of polymerisation and curing efficiency. Contrary to this, a higher concentration of photoinitiator does not guarantee a faster curing profile and may introduce defects into the networks due to high initiator residues.

\section{Effect of the organoalkoxysilane monomer and the ions inside the forming hybrid matrix}

The rate of radical propagation depends on the reactivity of the monomer used and the growing radical, as well as other structural factors, such as steric effects, polarity, and resonance. With regard to the steric effects, a bulky substituent on the monomer will typically result in a lower rate of polymerisation. A TMSPM monomer is not very viscous, even at the beginning of polymerisation, and, therefore, diffusional mobility is not reduced; the polymerising end group does not tend to be more sterically buried within the larger polymer coil. These effects result in an increased rate of bimolecular radical termination, which induces automatic acceleration [38].

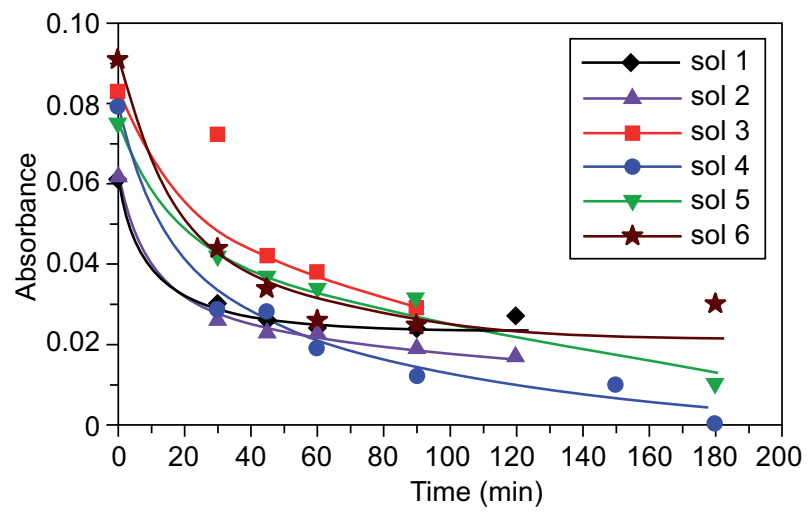

Figure 4. Kinetics of sols 1-6 polymerised by Irgacure 819 containing different ions and their combination. 
We assume that the presence of ions, particularly copper ions and/or their combination with silver in the presence of silica dioxide-titanium dioxide matrix, may influence the speed of the double bond conversion. Copper can work as a catalyst during the UV curing process due to its tendency to interact with many organic ligands, oxygen, water molecules and/or hydroxyl ions. Moreover, considering the photoinitiators structure and surplus of copper ions inside the forming hybrid matrix, we assume that copper ions may play an important role in the slowing down the polymerisation process, see Figures 3 and 4 . As a result, the newly forming organic matrix most probably polymerises too fast while simultaneously drawing away the end chains of methacrylate and thus slows down the double bond conversion. The mentioned effect was observed in the case of sols 3,5 and 6 , where copper ions were present together with both the tested photoinitiators. The obtained results indicate that the other two tested ions, silver (sols 2) and zinc (sols 4), do not have a strong or direct effect on the polymerisation process.

\section{CONCLUSION}

This work deals with the optimisation of the polymerisation conditions induced by UV A light, particularly for sol 6 containing a combination of silver, copper and zinc ions. The polymerisation process was implemented with the two commercially available photoinitiators Darocur 1173 and Irgacure 819. However, in both cases, a $50 \%$ conversion of the double bonds was achieved for sol 6 containing all three types of ions. Contrary to this, the double bond conversion, reaching almost $95 \%$ in 120 minutes, has been achieved with sol 1 containing pure TMSPM, in combination with Darocur 1173. The presence of copper ions inside the hybrid matrix may influence the speed of the double bond conversion. Copper can work as a catalyst during the polymerisation process due to its tendency to interact with many organic ligands, oxygen, and/or hydroxyl ions. Moreover, when we think about the photoinitiators structure and the surplus of copper ions inside the forming hybrid matrix, these mentioned factors may play a role in the slowing down the polymerisation process, where copper was present.

\section{Acknowledgement}

This work was supported by the Ministry of Education, Youth and Sports of the Czech Republic and the European Union - European Structural and Investment Funds in the frames of Operational Programme Research, Development and Education project Hybrid Materials for Hierarchical Structures (HyHi, Reg. No. CZ.02.1.01/0.0/0.0/16 019/0000843), the OPR\&DI project "Extension of CXI facilities"
(CZ.1.05/2.1.00/19.0386) and the project SGS 21207, Faculty of Science, Humanities and Education, Technical University of Liberec.

\section{REFERENCES}

1. Jaiswal S., McHale P., Duffy B. (2012): Preparation and rapid analysis of antibacterial silver, copper and zinc doped sol-gel surfaces. Colloids Surface B Biointerfaces, 94, 170-176 . doi: 10.1016/j.colsurfb.2012.01.035

2. Sundberg P., Karppinen M. (2014): Organic-Inorganic Thin Films from TiCl4 and 4-Aminophenol Precursors: A Model Case of ALD/MLD Hybrid-Material Growth? European Journal of Inorganic Chemistry, 2014, 968-974 . doi: 10.1002/ejic.201301560

3. Wang H., Dai H. (2013): Strongly coupled inorganic-nanocarbon hybrid materials for energy storage. Chemical Society Reviews, 42, 3088-3113. doi: 10.1039/C2CS35307E

4. Lebeau B., Innocenzi P. (2011): Hybrid materials for optics and photonics. Chemical Society Reviews, 40,886-906. doi: 10.1039/C0CS00106F

5. Nicole L., Rozes L., Sanchez C. (2010): Integrative Approaches to Hybrid Multifunctional Materials: From Multidisciplinary Research to Applied Technologies. Advanced Materials, 22, 3208-3214. doi: 10.1002/adma. 201000231

6. Ronkainen N.J., Okon S.L. (2014): Nanomaterial-Based Electrochemical Immunosensors for Clinically Significant Biomarkers. Materials, 7, 4669-4709. doi:10.3390/ma 7064669

7. Zuo Y., Liu X., Wei D., et al (2015): Photo-Cross-Linkable Methacrylated Gelatin and Hydroxyapatite Hybrid Hydrogel for Modularly Engineering Biomimetic Osteon. ACS Applied Materials Interfaces, 7, 10386-10394. doi: 10.1021/acsami.5b01433

8. Ozan Aydin G., Bulbul Sonmez H. (2016): Organic-inorganic hybrid gels for the selective absorption of oils from water. Environmental Science and Pollution Research International, 23, 11695-11707. doi: 10.1007/s11356-016$6342-9$

9. Zhang H., Ou J., Liu Z., Wang H., Wei Y., Zou H. (2015): Preparation of Hybrid Monolithic Columns via "OnePot" Photoinitiated Thiol-Acrylate Polymerisation for Retention-Independent Performance in Capillary Liquid Chromatography. Analytical Chemistry, 87, 8789-8797. doi: 10.1021/acs.analchem.5b01707

10. Toshima N., Oshima K., Anno H., Nishinaka T., Ichikawa S., Iwata A., Shiraishi Y. (2015): Novel Hybrid Organic Thermoelectric Materials:Three-Component Hybrid Films Consisting of a Nanoparticle Polymer Complex, Carbon Nanotubes, and Vinyl Polymer. Advanced Materials, 27, 2246-2251. doi: 10.1002/adma.201405463

11. Ohlmaier-Delgadillo F., Castillo-Ortega M.M., RamírezBon R., et al (2016): Photocatalytic properties of PMMA$\mathrm{TiO}_{2}$ class I and class II hybrid nanofibers obtained by electrospinning. Journal of Applied Polymer Science 133: n/a-n/a . doi: 10.1002/app.44334

12. Lalevée J., Poupart R., Bourgon J., Fouassier J. P., Versace D. L. (2015): In situ production of visible light absorbing Ti-based nanoparticles in solution and in a photopolymerizable cationic matrix. Chemical Communications, 51, 5762-5765. doi: 10.1039/C5CC01102G 
13. Levy D., Zayat M. (2015). The Sol-Gel Handbook: Synthesis, Characterization and Applications, 3-Volume Set. John Wiley \& Sons

14. Zhang L., Zeng Z., Yang J., Chen Y. (2004): Characterization and properties of UV-curable polyurethane-acrylate/silica hybrid materials prepared by the sol-gel process. Polymer Interfaces, 53,1431-1435. doi: 10.1002/pi.1536

15. Zajicova V., Exnar P., Stanova I. (2011): Properties of Hybrid Coatings Based on 3-trimethoxysilylpropyl methacrylate. Ceramics-Silicates, 55, 221-227.

16. Kawasumi M. (2004): The discovery of polymer-clay hybrids. Journal of Polymer Science Part Polymer Chemistry, 42, 819-824 . doi: 10.1002/pola.10961

17. Pyun J., Matyjaszewski K. (2001): Synthesis of Nanocomposite Organic/Inorganic Hybrid Materials Using Con-trolled/“Living" Radical Polymerisation. Chemistry Materials, 13, 3436-3448 . doi: 10.1021/cm011065j

18. Belon C., Chemtob A., Croutxé-Barghorn C., Rigolet S., Le Houérou V., Gauthier C. (2011): A Simple Method for the Reinforcement of UV-Cured Coatings via Sol-Gel Photopolymerisation. Macromolecular Materials and Engineering, 296, 506-516. doi: 10.1002/mame.201000350

19. Soucek M.D., Johnson A.H., Meemken L.E., Wegner J.M. (2005): Preparation of nano-sized UV-absorbing titaniumoxo-clusters via a photo-curing ceramer process. Polymers for Advanced Technologies, 16, 257-261. doi: 10.1002/ pat.563

20. Mohseni M., Bastani S., Jannesari A. (2014): Influence of silane structure on curing behavior and surface properties of sol-gel based UV-curable organic-inorganic hybrid coatings. Progress in Organic Coatings, 77, 1191-1199. doi: 10.1016/j.porgcoat.2014.04.008

21. Nebioglu A., Soucek M.D. (2007): Reaction kinetics and network characterization of UV-curing polyester acrylate inorganic/organic hybrids. European Polymer Journal, 8, 3325-3336. doi: 10.1016/j.eurpolymj.2007.05.035

22. Dashtizadeh A., Abdouss M., Khorassani M., Mahdavi H. (2012): Preparation of silica-filled water-based acrylic nanocomposite paints with improved scratch resistance. Journal of Plastic Film \& Sheeting, 28, 120-135. doi: 10.1177/8756087911421702

23. Zhao L., Wang H., Huo K., et al (2011): Antibacterial nano-structured titania coating incorporated with silver nanoparticles. Biomaterials, 32, 5706-5716. doi: 10.1016/ j.biomaterials.2011.04.040

24. Kang K.S., Kim B.J., Jo D.H., et al (2014). Temperature dependent surface modification of silica spheres with methacrylate. in: Proceedings of. SPIE 9160, Metamaterials: Fundamentals and Applications, 9160, pp. 916021. doi: 10.1117/12.2061456

25. Maleki H., Durães L., García-González C.A., del Gaudio P., Portugal A., Mahmoudi M. (2016): Synthesis and biomedical applications of aerogels: Possibilities and challenges. Advances in Colloid and Interface Science, 236, 1-27. doi: 10.1016/j.cis.2016.05.011

26. Bersani D., Lottici P.P., Tosini L., Montenero A. (1999): Raman Study of the Polymerisation Processes in Trimethoxysilylpropyl Methacrylate (TMSPM). Journal of Raman
Spectroscopy, 30, 1043-1047. doi: 10.1002/(SICI)10974555(199911)30:11<1043::AID-JRS480>3.0.CO;2-Q

27. Dallas P., Sharma V.K., Zboril R. (2011): Silver polymeric nanocomposites as advanced antimicrobial agents: Classification, synthetic paths, applications, and perspectives. Advances in Colloid and Interface Science,166, 119-135. doi: 10.1016/j.cis.2011.05.008

28. Ruparelia J.P., Chatterjee A.K., Duttagupta S.P., Mukherji S. (2008): Strain specificity in antimicrobial activity of silver and copper nanoparticles. Acta Biomaterialia ,4, 707-716 . doi: 10.1016/j.actbio.2007.11.006

29. Blaser S.A., Scheringer M., Macleod M., Hungerbühler K. (2008): Estimation of cumulative aquatic exposure and risk due to silver: contribution of nano-functionalized plastics and textiles. Science of the Total Environment , 390, 396 409. doi: 10.1016/j.scitotenv.2007.10.010

30. Šlamborová I., Zajícová V., Karpíšková J., Exnar P., Stibor I. (2013): New type of protective hybrid and nanocomposite hybrid coatings containing silver and copper with an excellent antibacterial effect especially against MRSA. Materials Science and Engineering: C,33, 265-273. doi: 10.1016/j.msec.2012.08.039

31. Larrañeta E., McCrudden M.T.C., Courtenay A.J., Donnelly R.F. (2016): Microneedles: A New Frontier in Nanomedicine Delivery. Pharmaceutical Research, 33, 1055-1073. doi: 10.1007/s11095-016-1885-5

32. Schizas C., Karalekas D. (2011): Mechanical characteristics of an Ormocomp(®) biocompatible hybrid photopolymer. Journal of the Mechanical Behavior of Biomedical Materials, 4, 99-106. doi: 10.1016/j.jmbbm.2010.09.010

33. Lee B.K., Park K.S., Kim D.P., et al (2012): Siliconized silsesquioxane-based nonstick molds for ultrahigh-resolution lithography. Journal of Materials Chemistry, 22, 16754-16760. doi: 10.1039/c2jm32386a

34. Yang B., Parada C.M., Storey R.F. (2016): Synthesis, Characterization, and Photopolymerisation of Polyisobutylene Phenol (Meth)acrylate Macromers. Macromolecules, 49, 6173-6185. doi: 10.1021/acs.macromol.6b01289

35. Hodek J., Zajícová V., Lovětinská-Šlamborová I., et al (2016): Protective hybrid coating containing silver, copper and zinc cations effective against human immunodeficiency virus and other enveloped viruses. BMC Microbiology, 16, 56, 2-12. doi: 10.1186/s12866-016-0675-x

36. Decker C. (1998): The use of UV irradiation in polymerisation. Polymer International, 45, 133-141. doi: $\quad 10.1002 /($ SICI) 1097-0126(199802)45:2<133::AIDPI969>3.0.CO;2-F

37. Tripathy R., Crivello J.V., Faust R. (2013): Photoinitiated polymerisation of acrylate, methacrylate, and vinyl ether end-functional polyisobutylene macromonomers. Journal of Polymer Science Part A: Polymer Chemistry, 51, 305-317. doi: 10.1002/pola.26379

38. White TJ., Liechty W.B., Guymon A. (2007): The influence of $\mathrm{N}$-vinyl pyrrolidone on polymerisation kinetics and thermo-mechanical properties of crosslinked acrylate polymers. Journal of Polymer Science Part A: Polymer Chemistry, 45, 4062-4073. doi: 10.1002/pola.22173 